\title{
Synthesis of the first mixed-donor spiro-linked macrocyclic tetralactams
}

\author{
Ahmed H. M. Elwahy, ${ }^{a, b}$ Hussni A. Muathen, ${ }^{a}$ and Nour A. M. Aloweiny ${ }^{\mathrm{a}}$ \\ ${ }^{a}$ Makkah Almukkarramah, P. O. Box 6503 unit 113, Saudi Arabia \\ ${ }^{b}$ Chemistry Department, Faculty of Science, Cairo University, Giza, Egypt \\ E-mail:aelwahy@hotmail.com
}

\begin{abstract}
A synthesis of spiro-linked macrocyclic tetraamides 1 and $\mathbf{2}$ was accomplished by the reaction of pentaerythrityl tetrabromide $\mathbf{1 3}$ with two moles of the appropriate dipotassium salts $\mathbf{5 a}$ and $\mathbf{5 b}$ in refluxing DMF. Treatment of $\mathbf{1}$ and $\mathbf{2}$ with Lawesson's reagent in refluxing toluene afforded the novel spiro-linked macrocyclic tetrathiotetraamides 14 and 15, respectively.
\end{abstract}

Keywords: Alkylation, thiation, macrocyclic diamides, macrocyclic dithiodiamides, spiro-linked macrocycles

\section{Introduction}

The pioneering work of Pedersen, ${ }^{1} \mathrm{Lehn}^{2}$ and $\mathrm{Cram}^{3}$ on the syntheses of macrocyclic and macropolycyclic host systems such as crown ethers, azacrown ethers, cryptands and spherands, has generated a great amount of interest in host-guest chemistry. These macrocycles have been shown to exhibit important applications including selective ion separation and detection, molecular recognition, catalysis, biological applications as well as many other interesting applications in diverse fields of supramolecular chemistry. ${ }^{4}$ Of particular interest are crown ethers incorporating amide groups. It was reported that such groups modify the binding properties of the crown compounds with respect to alkali metal ions. ${ }^{5}$ Furthermore, macrocyclic amides are precursors in the preparation of azacrown ethers and cryptands. ${ }^{4}$ Some diamidecontaining macrocycles have been utilized as new catalysts. ${ }^{6}$ Moreover, special interest has been directed in recent years, toward the synthesis of bis(macrocycles) as well as multi-site crown compounds which are capable of binding simultaneously to two or more metal ions. ${ }^{7}$ Ligands capable of simultaneously being involved in two binding interactions are attracting current interest due to their applications in molecular recognition. ${ }^{8}$ A number of such compounds has been observed to act as anti-HIV agents, which exhibited low cytotoxicity. ${ }^{9}$ Bifunctional ligands 
may also have versatile properties in stereoselective catalysis due to their ability to be engaged in secondary interactions with the substrate undergoing reaction. ${ }^{10}$

In continuation of the above studies, we report here on the first synthesis of spiro-linked macrocycles tetraamides $\mathbf{1}$ and $\mathbf{2}$ which are expected to have ability to bind more than one metal ion.

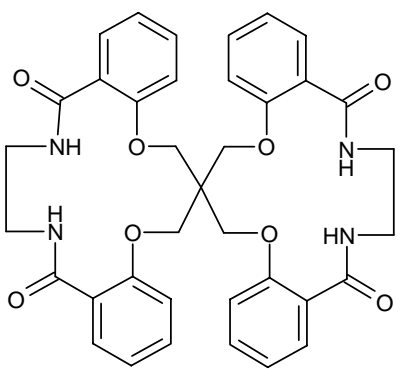

1

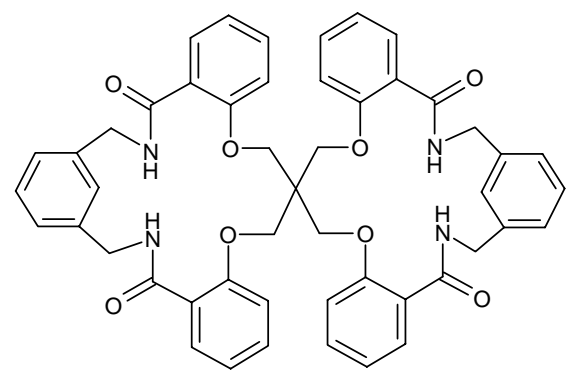

2

It is noteworthy to mention that Weber ${ }^{11}$ and Inoue et $\mathrm{al}^{12}$ pioneered the synthesis of the first spiro crown ethers 3 starting from pentaerythritol using stepwise cyclization techniques.

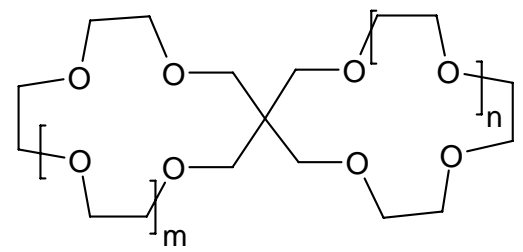

3, $m, n=1,2,3$

Previously, we reported the synthesis of dibenzo- and tribenzosubstituted macrocyclic diamides $\mathbf{7}$ by the reaction of the potassium salts $\mathbf{5 a}$ and $\mathbf{5 b}$ (obtained upon treatment of the appropriate bis(phenols) $\mathbf{4 a}$ and $\mathbf{4 b}$ with ethanolic $\mathrm{KOH}$ ) with the corresponding dihalo compounds 6 in refluxing DMF under conventional heating methods as well as under microwave irradiation conditions (Scheme 1). ${ }^{13}$

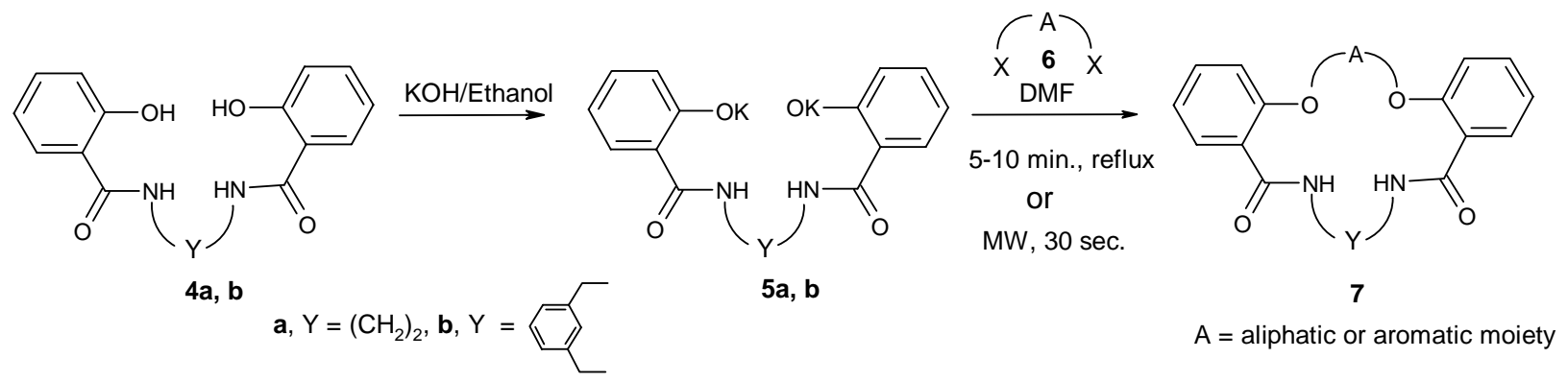

\section{Scheme 1}


Monocrown ethers of type 7 prefer sizes of metal ions, depending on the ring size of the macrocycle. It had been reported ${ }^{14}$ that the bis-crown effect occurs when two crown ether rings in one molecule bind a cation in a sandwich-type structure, and it enables the molecules to bind a cation that is larger than the ideal size for particular crown ether unit. To improve the cation binding abilities of the macrocycles 7 , we have recently reported the synthesis of macrocyclic diamide with pendant hydroxyl group $\mathbf{8}$ which can be successfully utilized as a key intermediate for the synthesis of the bis (macrocyclic diamides) $9 .{ }^{15}$

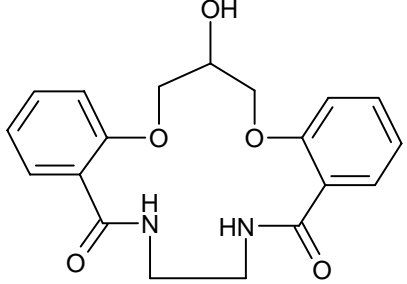

8

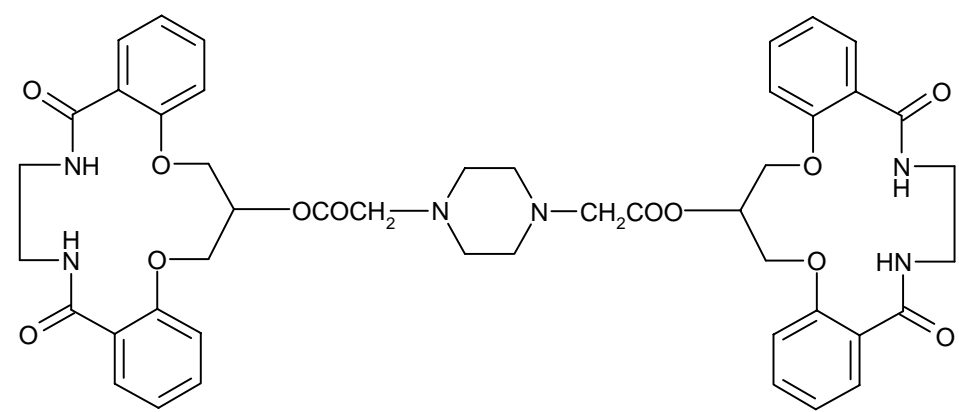

9

\section{Results and Discussion}

As part of our continuing effort in this area we investigated two strategies for the synthesis of the target compounds $\mathbf{1}$ and 2. In the first strategy, we studied the synthesis of the dihydroxy macrocycles 11 which should then undergo bromination with $\mathrm{PBr}_{3}$ to give the dibromo compounds 12. Subsequent reaction with another equivalent of $\mathbf{5 a}$ and $\mathbf{5 b}$ should give the target spiro macrocycles $\mathbf{1}$ and 2, respectively (Scheme 2).

Unfortunately, we were not able to isolate a pure sample of the corresponding dihydroxy derivatives 11 by the reaction of 2,2-bis(bromomethyl)-1,3-propanediol 10 with one equivalent of the appropriate potassium salt $\mathbf{5 a}$ and $\mathbf{5 b}$ in refluxing DMF.

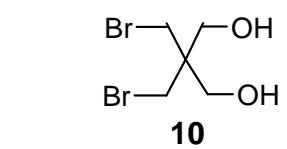

$5 a, b$
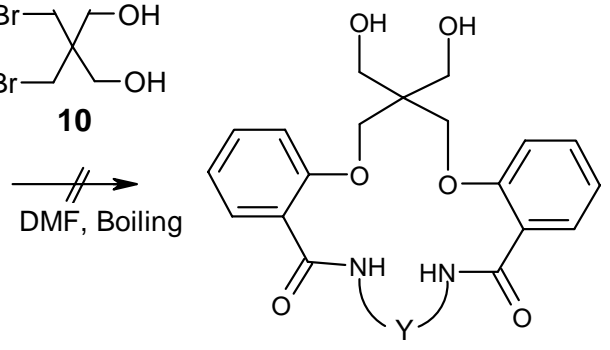

11a,b

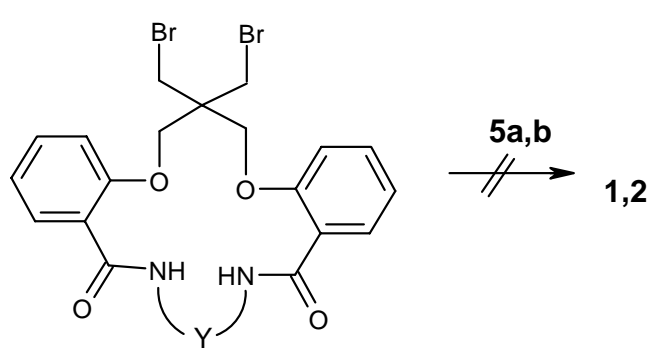

$12 a, b$

$\mathbf{a}, \mathrm{Y}=\left(\mathrm{CH}_{2}\right)_{2}, \mathbf{b}, \mathrm{Y}=\mathbb{}$

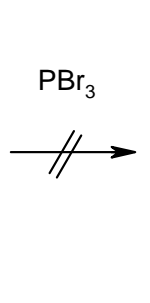

0()$\left.^{\prime}\right)_{0}$

\section{Scheme 2}


In the second strategy (Scheme 3) we applied a one-step synthesis of $\mathbf{1}$ and $\mathbf{2}$ utilizing pentaerythrityl tetrabromide $\mathbf{1 3}$ as a starting material. Thus, reaction of $\mathbf{1 3}$ with two moles of the appropriate dipotassium salts $\mathbf{5 a}$ and $\mathbf{5 b}$ in refluxing DMF afforded the corresponding spirolinked macrocycles 1 and 2 in $52 \%$ and $44 \%$ yields, respectively. Physical measurements $\left({ }^{1} \mathrm{H}\right.$ and ${ }^{13} \mathrm{C}$-NMR, mass spectra) as well as elemental analyses were in accordance with the structure proposed for the latter compounds.

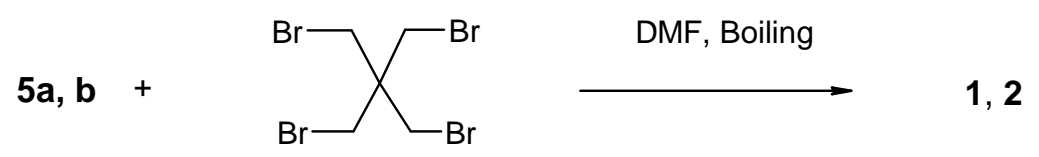

13

\section{Scheme 3}

The novel spiro macrocyclic tetraamides, now available, prompted us to study their possible transformation to their corresponding tetrathiotetraamide derivatives. Thus, the novel macrocycles 14 and 15 were prepared in $55 \%$ and $52 \%$ yields, respectively, upon treatment of each of the macrocyclic tetraamides $\mathbf{1}$ and $\mathbf{2}$ with Lawesson`s reagent in refluxing toluene for $6 \mathrm{~h}$. Thioamides are known to be weaker hydrogen-bond acceptors and stronger acids than amides. ${ }^{16}$ For these reasons, thioamides are attractive groups for the construction of anion hosts.

The ${ }^{1} \mathrm{H}$ NMR and ${ }^{13} \mathrm{C}$ NMR data of the spiro macrocycles 1, 2, 14, and 15, showed magnetic equivalence of the $\mathrm{OCH}_{2}$ and $\mathrm{NCH}_{2}$ protons which indicates rapid exchange in these macrocycles.

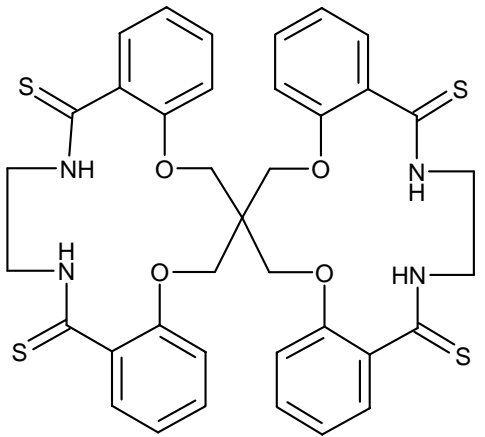

14

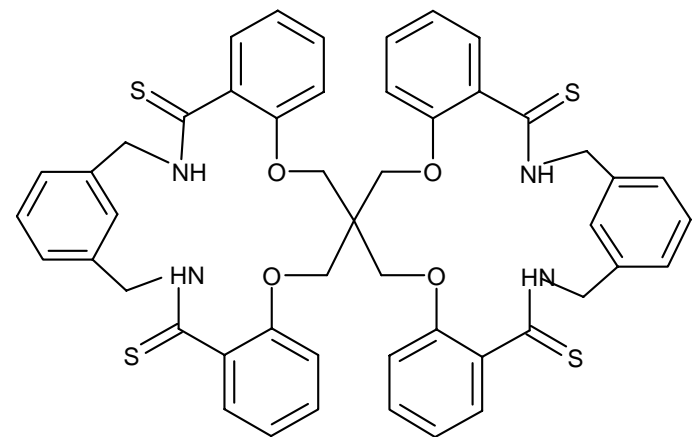

15

\section{Conclusions}

We prepared the first spiro-linked macrocyclic tetraamides $\mathbf{1}$ and $\mathbf{2}$ as well as their corresponding spiro-linked macrocyclic tetrathiotetraamides 14 and 15. The new synthesized macrocycles offer an advantage of their easy synthesis in a simple one step procedure from inexpensive starting 
materials. In addition, the presence of the thioamide groups allows functionalization of the new macrocycles to produce side armed ligands which permit a more dynamic complexation of metal ions. We believe that these new series of compounds should exhibit useful analytical uses on account of their abilities to bind more than one metal ion. Comparison of the binding abilities of the new macrocycles with their corresponding single-ring derivatives 7 as well as the bis macrocycle 9, in which two macrocyclic dilactam units are connected by a flexible bridge, is still underway.

\section{Experimental Section}

General Procedures. Melting points are uncorrected. IR spectra $(\mathrm{KBr})$ were recorded on a Perkin-Elmer 1430 spectrophotometer. NMR spectra were measured with a Varian Mercury 300 $\left(300 \mathrm{MHz}{ }^{1} \mathrm{H}\right.$ NMR, $75 \mathrm{MHz}{ }^{13} \mathrm{C}$ NMR) spectrophotometer and chemical shifts are given in ppm from TMS. Mass spectra were recorded on a GC MS-QP1000 EX (70 eV) or MS $5988(15 \mathrm{eV})$ spectrometers. Elemental analyses were carried out at the Microanalytical Centre, Cairo University.

\section{Preparation of the potassium salts (5a and $5 b$ )}

To a solution of $\mathrm{KOH}(1.14 \mathrm{~g}, 10 \mathrm{mmol})$ in methanol $(10 \mathrm{ml})$ was added the bis-phenol 4a,b (5 $\mathrm{mmol}$ ). The mixture was stirred at room temperature for $10 \mathrm{~min}$. The solvent was then removed in vacuo. The remaining solid was triturated with dry ether, collected, dried, and used in the next step without further purification.

\section{Synthesis of macrocycles 1 and 2. General procedure}

A solution of the appropriate potassium salts of $\mathbf{5 a}$ and $\mathbf{5 b}(10 \mathrm{mmol})$ and the pentaerythrityl tetrabromide $13(10 \mathrm{mmol})$ in DMF $(20 \mathrm{ml})$ was heated under reflux for $30 \mathrm{~min}$. during which time $\mathrm{KBr}$ precipitated. The solvent was then removed in vacuo and the remaining material was washed with water $(50 \mathrm{ml})$ and purified by crystallization from ethanol and dioxane, respectively, to give colorless crystals of $\mathbf{1}$ and $\mathbf{2}$, respectively.

Spiro macrocycle 1. With the use of the general procedure 5a and 13 gave 1 (52 \%), mp 182$183{ }^{\circ} \mathrm{C}$. IR: 3388, $3274(\mathrm{NH}), 1645(\mathrm{C}=\mathrm{O}) \mathrm{cm}^{-1}$; ${ }^{1} \mathrm{H}$ NMR (DMSO-d 6 ) $\delta 3.16\left(\mathrm{br}, 8 \mathrm{H}, \mathrm{CH}_{2} \mathrm{NH}\right)$, $4.52\left(\mathrm{~s}, 8 \mathrm{H}, \mathrm{OCH}_{2}\right), 7.04-7.63\left(\mathrm{~m}, 16 \mathrm{H}, \mathrm{ArH}\right.$ 's), 8.24 (br, 4H, NH) ppm; ${ }^{13} \mathrm{C}$ NMR (DMSO) $\delta$ $43.25\left(\mathrm{CH}_{2} \mathrm{NH}\right), 48.53\left(\mathrm{C}\left(\mathrm{CH}_{2}\right)_{4}\right), 71.07\left(\mathrm{OCH}_{2}\right), 113.11,121.06,124.34,129.89,131.60,155.69$ (ArC's), $165.22(\mathrm{C}=\mathrm{O})$; MS (FD): m/z $(\%)=665(100)\left[\mathrm{M}^{+}+1\right]$; Anal. Calcd for $\mathrm{C}_{37} \mathrm{H}_{36} \mathrm{O}_{8} \mathrm{~N}_{4}$ (664.72): C, 66.86; H, 5.46; N, 8.43; Found: C, 66.70; H, 5.70; N, 8.20.

Spiro macrocycle 2. With the use of the general procedure $5 \mathbf{b}$ and 13 gave 2 (44\%), mp 189$191{ }^{\circ} \mathrm{C}$. IR: $3410(\mathrm{NH}), 1646(\mathrm{C}=\mathrm{O}) \mathrm{cm}^{-1} ;{ }^{1} \mathrm{H}$ NMR (DMSO-d $) \delta 4.16\left(\mathrm{~s}, 8 \mathrm{H}, \mathrm{OCH}_{2}\right), 4.49(\mathrm{~d}, J$ $\left.=5.7 \mathrm{~Hz}, 8 \mathrm{H}, \mathrm{CH}_{2} \mathrm{NH}\right), 6.51-7.67(\mathrm{~m}, 24 \mathrm{H}, \mathrm{ArH} \mathrm{s}), 8.41(\mathrm{t}, J=5.7 \mathrm{~Hz}, 4 \mathrm{H}, \mathrm{NH}) \mathrm{ppm} ;{ }^{13} \mathrm{C} \mathrm{NMR}$

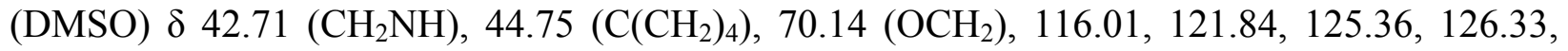


127.24, 128.51, 129.97, 131.83, 139.27, 155.95 (ArC's), $164.98(\mathrm{C}=\mathrm{O}) ; \mathrm{MS}(\mathrm{FD}): \mathrm{m} / \mathrm{z}(\%)=816$ (100) $\left[\mathrm{M}^{+}\right]$; Anal. Calcd for $\mathrm{C}_{49} \mathrm{H}_{44} \mathrm{O}_{8} \mathrm{~N}_{4}$ (816.92): C, 72.05; H, 5.43; N, 6.86; Found: C, 72.30; $\mathrm{H}, 5.60 ; \mathrm{N}, 6.50$.

\section{Thiation of the macrocyclic 1 and 2. General procedure}

To a boiling solution of 1 and $2(10 \mathrm{mmol})$ in toulene $(30 \mathrm{ml})$ was added Lawesson's reagent $(8.1$ $\mathrm{g}, 20 \mathrm{mmol})$. The reaction mixture was heated under reflux for $3 \mathrm{~h}$. After cooling the yellow precipitate was collected and crystallized from $\mathrm{EtOH} / \mathrm{H}_{2} \mathrm{O}$ to give yellow crystals of 14 and 15, respectively.

Spiro macrocycle 14. With the use of the general procedure 1 gave 14 (55\%), mp. 298-300 ${ }^{\circ} \mathrm{C}$. IR $\left(\mathrm{cm}^{-1}\right) 3176(\mathrm{NH}) ;{ }^{1} \mathrm{H}$ NMR (DMSO) $\delta 4.03\left(\mathrm{~s}, 8 \mathrm{H}, \mathrm{CH}_{2} \mathrm{O}\right), 4.28\left(\mathrm{~s}, 8 \mathrm{H}, \mathrm{CH}_{2} \mathrm{NH}\right), 7.05-7.55$ (m, 12H, ArH's), 10.08 (br, 4H, NH); Anal. Calcd for $\mathrm{C}_{37} \mathrm{H}_{36} \mathrm{~N}_{4} \mathrm{O}_{4} \mathrm{~S}_{4}$ (728.99): C, 60.96; H, 4.98; N, 7.69; Found: C, 60.60; H, 4.90; N, 7.40.

Spiro macrocycle 15. With the use of the general procedure 2 gave $15(52 \%), \mathrm{mp} .276-278{ }^{\circ} \mathrm{C}$. IR $\left(\mathrm{cm}^{-1}\right) 3295(\mathrm{NH}) ;{ }^{1} \mathrm{H}$ NMR (DMSO) $\delta\left(3.97\left(\mathrm{~s}, 8 \mathrm{H}, \mathrm{CH}_{2} \mathrm{O}\right), 4.96\left(\mathrm{~s}, 8 \mathrm{H}, \mathrm{CH}_{2} \mathrm{NH}\right), 6.30-7.62\right.$ (m, 24H, ArH's), 10.43 (br, 4H, NH); Anal. Calcd for $\mathrm{C}_{49} \mathrm{H}_{44} \mathrm{~N}_{4} \mathrm{O}_{4} \mathrm{~S}_{4}$ (881.18): C, 66.79; H, 5.03; N, 6.36; Found: C, 66.60; H, 4.90; N, 6.40.

\section{References}

1. (a) Pedersen, C. J. J. Am. Chem. Soc. 1967, 89, 7017. (b) Pedersen, C. J. J. Am. Chem. Soc. 1970, 92, 386. (c) Pedersen, C. J. Angew. Chem., Int. Ed. 1988, 27, 1021.

2. Lehn, J. M. Angew. Chem., Int. Ed. 1988, 27, 89.

3. Cram, D. J. Angew. Chem., Int. Ed. 1988, 27, 1009.

4. (a) Bradshaw, J. S.; Izatt, R. M.; Bordunov, A. V.; Zhu, C. Y.; Hathaway, J. K. In Comprehensive Supramolecular Chemistry; Gokel, G. W., Ed.; Pergamon: New York, 1996; Vol 1, p 35. (b) Izatt, R. M.; Bordunov, A. V.; Zhu, C. Y.; Hathaway, J. K. In Comprehensive Supramolecular Chemistry; Gokel, G. W., Ed.; Pergamon: New York, 1996; Vol 1, p 3595. (c) Dietrich, B. In Comprehensive Supramolecular Chemistry; Gokel, G. W., Ed.; Pergamon: New York, 1996; Vol 1, p 153. (d) Gokel, G. W.; Federes, M. F. In Comprehensive Heterocyclic Chemistry; Elsevier: Oxford, 1996; Vol. 9, p 863. (e) Krakowiak, K. E.; Bradshaw, J. S.; Zamecka-Krakowiak, D. J. Chem. Rev. 1989, 89, 929. (f) Elwahy, A. H. M. J. Heterocycl. Chem. 2003, 40, 1. (g) Gokel, G. W.; Leevy, W. M.; Weber, M. E. Chem. Rev. 2004, 104, 2723. (h) Ibrahim,Y. A.; Abbas, A. A.; Elwahy, A. H. M. J. Heterocycl. Chem. 2004, 41, 135. (i) Izatt, R. M.; Pawlak, K.; Bradshaw, J. S.; Bruening, R. L. Chem Rev. 1991, $91,1721$.

5. (a) Kumar, S.; Singh. R.; Singh. H. Bioorg. Med. Chem. Lett. 1993, 3, 363. (b) Kumar, S; Kaur, N.; Singh, H. Tetrahedron 1996, 52, 13483. (c) Kumar, S.; Kaur, N.; Singh. H. Tetrahedron Lett. 1996, 37, 2071. (d) Mitchell, M. C.; Cawley, A.; Kee, T. P. Tetrahedron 
Lett. 1995, 36, 287. (e) Fujita, T.; Lehn, J.-M. Tetrahedron Lett. 1988, 29, 1709. (f) Trafton, Y. E.; Mallen, C. L. J.; Miller, S. R.; Nakano, A.; Schall, O. F.; Gokel, G. W. J. Chem. Soc., Chem. Commun. 1990, 1266.

6. Sharghi, H.; Massah, A. R.; Eshgi, H.; Niknam, K. J. Org. Chem. 1998, 63, 1455.

7. (a) Carroy, A.; Lehn, J. M. J. Chem. Soc., Chem. Commun. 1986, 1232. (b) Bourguignon, J.; Bremberg, U.; Dupas, G.; Hallman, K.; Hagberg, L.; Hortala, L.; Levacher, V.; Lutsenko, S.; Macedo, E.; Moberg, C.; Queguinera, G.; Rahmb, F. Tetrahedron 2003, 59, 9583. (c) Morey, J.; Orell, M.; Barcelo, M. A.; Deya, P. M.; Costa, A.; Ballester, P. Tetrahedron Lett. 2004, 45, 1261. (d) Elwahy, A. H. M.; Abbas, A. A. Tetrahedron Lett. 2006, 47, 1303. (e) Huang, Z. B.; Kang, T. J.; Chang, S. H. Tetrahedron Lett. 2005, 46, 3461. (f) Huang, Z. B.; Chang, S. H. Tetrahedron Lett. 2005, 46, 5351. (g) Huang, Z. B.; Kang, T. J.; Chang, S. H. Tetrahedron Lett. 2005, 46, 3461. (h) Huang, Z. B.; Chang, S. H. Tetrahedron Lett. 2005, 46, 5351. (i) Murashima, T.; Uchihara, Y.; Wakamori, N.; Uno, H.; Ogawa, T.; Ono, N. Tetrahedron Lett. 1996, 37, 3133. (j) Shinmori, H.; Furuta, H.; Osuka, A. Tetrahedron Lett. 2000, 41, 8527. (k) Shinmori, H.; Furuta, H.; Osuka, A. Tetrahedron Lett. 2002, 43, 4881. (1) Chambron, J. C.; Sauvage, J. P. Tetrahedron Lett. 1986, 27, 865. (m) Sousa, C.; Gameiro, P.; Cristina Freire, C.; de Castro, B. Polyhedron 2004, 23, 1401. (n) Kocak, M.; Okur, A. C.; Gul, A.; Bekaroglu, O. Dyes Pigments 2000, 45, 9. (o) An, H.; Bradshaw, J. S.; Izzat, R. M.; Yan, Z. Chem Rev. 1994, 94, 939.

8. Kryatova, O. P.; Kolchinski, A. G.; Rybak-Akimova, E. V. Tetrahedron 2003, 59, 231.

9. Bridger, G. J.; Skerlj, R. T.; Thornton, D.; Padmanabhan, S.; Martellucc, S. A.; Henson, G. W.; Abrams, M. J.; Yamamoto, N.; De Vreese, K.; Pauwels, R.; De Clerck, E.; J. Med. Chem. 1995, 38, 366.

10. (a) van den Beuken, E. K.; Feringa, B. L. Tetrahedron 1998, 54, 12985. (b) Shibasaki, M.; Kanai, M.; Funabashi, K. Chem. Commun. 2002, 1998. (c) Shibasaki, M.; Yoshikawa, N. Chem. Rev. 2002, 102, 2187.

11. Weber, E. J. Org. Chem. 1982, 47, 3478.

12. Ouchi, M.; Inoue, Y.; Sakamoto, H.; Yamahira, A.; Yoshinaga, M.; Hakushi, T. J. Org. Chem. 1982, 48, 3168.

13. (a) Ibrahim, Y. A.; Elwahy, A. H. M. Synthesis 1993, 503. (b) Elwahy, A. H. M.; Masaret, Gh. S. J. Heterocycl. Chem. 2004, 41, 711. (c) Elwahy, A. H. M.; Abbas, A. A. Tetrahedron 2000, 56, 885. (d) Mohamed, A. A.; Masaret, Gh. S.; Elwahy, A. H. M. Tetrahedron 2007, 63, 4000 .

14. (a) Beer, P. D.; Crane, C. G.; Danks, J. P.; Gale, P. A.; McAleer, J. F. J. Organometallic Chem. 1995, 490, 143. (b) Lee, L.-H.; Lynch, V.; Lagow, R. J. Chem. Soc., Perkin Trans. 1 2000, 2805.

15. Abbas, A. A.; Elwahy, A. H. M.; Ahmed, A. A. M. J. Heterocycl. Chem. 2005, 42, 233.

16. (a) Zielinski, T.; Jurczak, J. Tetrahedron 2005, 61, 4081. (b) Zielinski, T.; Jurczak, J. Tetrahedron 2005, 61, 4081. (c) Lee, H.-J.; Choi, Y.-S.; Lee, K.-B.; Park, J.; Yoon. C.-J. J. Phys. Chem. A 2002, 106, 7010. 